\title{
Need Cost Effective Surgical Simulation, Send a Resident to the Hardware Store
}

Charles L Rodriguez-Feo', Colleen M Brophy² and

${ }^{1}$ Vanderbilt University School of Medicine, USA

${ }^{2}$ Vanderbilt University Medical Center, Division of Vascular Surgery, USA

${ }^{3}$ Vanderbilt University Medical Center, Division of General Surgery D4314 Medical Center North 21 ${ }^{\text {st }}$ Avenue South Nashville, TN 37232, USA

\begin{abstract}
Background: The purpose of this project was to design a novel, cost-effective simulator for a vascular surgery skills workshop. The simulator had to be realistic, durable, cost less than $\$ 10$ per unit to produce, and allow for practicing multiple vascular techniques. Vascular Surgery has a unique challenge in that vascular anastomoses are constructed at various apertures in body cavities making the surgeon constantly adapt.
\end{abstract}

Methods: After interviewing two vascular surgeons, the unifying themes identified were that the learner needed to practice multiple techniques (an end to side anastomosis, an end to end anastomosis, and the sewing of a patch) at various depths. Using these criteria, 18 simulators were created and 25 surgical interns attended a 2-hour workshop during which they were asked to perform the tasks mentioned above. Post-workshop, an online survey was administered.

Results: The number of vascular anastomoses performed prior to the workshop was 0 for $86 \%$ of respondents. During the workshop participants performed an average of 3 anastomoses and participated in an average of 6 anastomoses. On a visual analog scale, residents rated their ability to complete a vascular anastomosis subjectively higher after the workshop ( $p=.009$, Wilcoxon matched-pairs rank sum test). $100 \%$ of respondents would like to have the simulator for personal use and $71 \%$ were willing to pay for the simulator. $86 \%$ reported they would be comfortable demonstrating competency on the simulator prior to being able to perform the skill in the operating room.

Conclusions: This study demonstrates viability of inexpensive, durable, open vascular simulation with varying degrees of difficulty and techniques. Subjectively, the simulator led to an increased ability of residents to perform an anastomosis. All residents wished for a personal simulator to use in their home for practice, indicating that there is a market for personal simulators to be used as the learner desires.

Keywords: Vascular surgery; Vascular anastomoses; Vascular simulator

\section{Introduction}

Surgery is a demanding field that relies on very grounded, technical skill [1]. Practice has repeatedly been shown to have a substantial effect on surgical skill and competency [2]. Practice requires time and effort that isn't easily afforded during the present times with cut-backs in resident hours, a need for efficiency in the operating room, and a focus on patient well-being $[1,3]$. The old model of surgical education with sole practice through experience is being driven out by a new model of combined use of simulators and OR experience [3].

Medical simulation has become common place in medicine and surgery with examples dating back hundreds of years [4]. Surgical simulation has more recently been viewed as a bigger player in surgical education due to high-fidelity artificial tissues that have recently come on the market [5]. While these tissues are great learning tools, their cost and limited use make them a non-ideal tool for less-trained residents $[5,6]$. Basic skills can be acquired for a technique as long as the simulator demands the necessary level of motor skills [6].

Vascular anastomotic training relies on the acquisition of different techniques: end-to-end and end-to-side anastomoses are essential for any vascular surgeon (Technical considerations in the construction of vascular anastomoses). The current high-fidelity, one-use trainers only address one of these techniques while costing in excess of five hundred dollars. Described in this article is a way of producing a very low-budget simulator for vascular anastomoses. Many examples of lowbudget simulators are described in the literature [7-9].
A Vanderbilt resident challenged with the task designed this simulator. The parameters were that it had to cost less than 10 dollars and be reusable. The simulator was designed for a workshop given once a year to categorical and non-categorical surgery interns. Its usefulness and effectiveness was determined by a post-survey given to the residents who used it.

\section{Methods}

Two vascular surgeons were interviewed regarding the ideal characteristics of a vascular simulator. The unifying theme of the interviews was that the learner needed to practice multiple techniques (an end to side anastomosis, an end to end anastomosis, and the sewing of a patch) at various difficulties. Using these criteria, 18 simulators were created (Figure 1). The materials allow for multiple anastomotic depths by adjusting the copper tubing holding the Penrose drain or by rotating the basket.

*Corresponding author: Kevin W Sexton, 8229 Boone Trace, Nashville, TN 37221 , USA, Tel: 615-479-0244; Fax: 615-343-2050; E-mail: kevin.sexton@gmail.com

Received May 20, 2014; Accepted August 20, 2014; Published August 22, 2014

Citation: Rodriguez-Feo CL, Brophy CM, Sexton KW (2014) Need Cost Effective Surgical Simulation, Send a Resident to the Hardware Store. J Vasc Med Surg 2: 150. doi: 10.4172/2329-6925.1000150

Copyright: (ㄷ 2014 Rodriguez-Feo CL, et al. This is an open-access article distributed under the terms of the Creative Commons Attribution License, which permits unrestricted use, distribution, and reproduction in any medium, provided the original author and source are credited. 
Citation: Rodriguez-Feo CL, Brophy CM, Sexton KW (2014) Need Cost Effective Surgical Simulation, Send a Resident to the Hardware Store. J Vasc Med Surg 2: 150. doi: 10.4172/2329-6925.1000150

Page 2 of 5

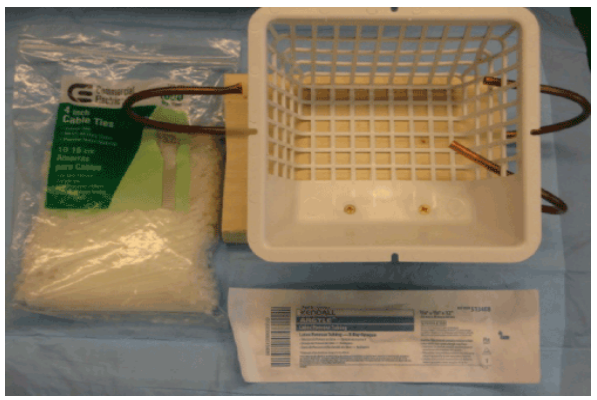

Figure 1: Vascular Trainer- View 1.

\begin{tabular}{|c|c|}
\hline \multicolumn{2}{|c|}{ Table 1: Materials } \\
\hline Item & Cost \\
\hline $2 \times 4 \times 16$ makes 28 Boards & $\$ 7.50$ \\
\hline $\begin{array}{c}\text { Universal Bird guard } \\
\text { (Lambro or Deflect- } 0 \text { ) }\end{array}$ & $\$ 2.50$ \\
\hline $\begin{array}{c}\text { 3/8 inch soft copper refridgiration Coiled Pipe } \\
-8 \text { inch Segment (20 ft. Coil makes 10 boxes) }\end{array}$ & $\$ 16.80$ \\
\hline Zip Ties (1000 ct) & $\$ 19.97$ \\
\hline Wood Screws (100 ct) & $\$ 4.00$ \\
\hline Penrose Drain & $\$ 1.50$ \\
\hline Per unit cost \$6.00 with penrose Drain
\end{tabular}

Table 1: Materials with cost estimates needed to build a vascular trainer.

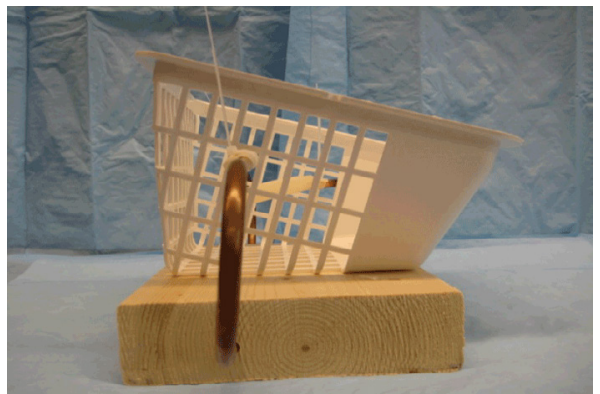

Figure 2: Vascular Trainer - View 2

\section{Supplies}

Supplies needed to build the vascular trainer are: a 2"x6" 66 " board to be the base, one universal bird guard, three 8 " segment of $3 / 8$ " soft copper refrigeration coiled pipe, 3 zip ties per use, 2 wood screws, and some penrose drain (at least $3 / 8$ inch diameter to fit over the pipe). Cost per unit is approximately $\$ 6$ (Table 1 ).

\section{Building a Trainer}

Trim a $2 \times 6$ to 6 inches. Drill a total of three $3 / 8$ " inch holes into the cut ends of the board: one on one side and two on the other making sure each is about 1.5 inches from each edge of the board (Figures 2 and 3). When drilling the holes, line up the single hole with one of the two on the other side. Next, secure the bird guard to the $2 \times 6$ using the wood screws making sure to center the bird guard on the wood. Line up the cage so that the holes of the basket are present on both the cut ends of the wood. Gently bend three pieces of 8" copper pipe into a C. Insert one end into each of the $3 / 8$ " holes in the wood. Direct the two opposite pipes into holes across from each other in the basket. Direct the last pipe into a hole in the basket about three inches away from the other pipe on the same side. Allow the third pipe about an inch and a half inside the basket and direct its path toward the imaginary center of the other two pipes. Trim a piece of penrose pipe to fit between the two opposite pipes and a second piece to span the distance from the third pipe to the imaginary center of the other two. Be generous now to allow for trimming later. Fit the penrose pipe to the copper tubing with zip ties and trim now as needed. Cut the penrose drain to allow for end to end, end to side, and patch repairs as displayed in Figures 4.

\section{Workshop}

Twenty-six first year surgery residents attended a 2-hour workshop during which they were asked to perform an end to end anastomosis, an end to side anastomosis, and the on-lay of a patch. Post-workshop, an online survey was sent to the group that had attended and data was collected using Research Electronic Data Capture (REDCap) (Figure 5) 10 .

\section{Results}

$14 / 26$ participants responded for total response rate of 54\%. The number of vascular anastomoses performed prior to the workshop was 0 for $86 \%$ of respondents. During the workshop participants performed an average of 3 anastomoses and participated in an average of 6 anastomoses. On a visual analog scale of 1-100 $\mathrm{mm}$ ( $1=$ no ability; $100=$ high ability of expertise) the respondents were asked to rate their ability to perform a vascular anastomosis prior to and after using the simulator (Figure 6). These results were statistically significant using a paired Wilcoxon matched-pairs rank sum test $(\mathrm{p}=.009)$ (Figure 7). Additionally, the trainer rated highly regarding ease of use, durability, and realism by learners (Figure 3). $100 \%$ of respondents would like to have the simulator for personal use. $71 \%$ of respondents $(10 / 14)$ were willing to pay for the simulator, with the average price being $\$ 25$ per unit. $86 \%(12 / 14)$ of respondents reported they would be comfortable

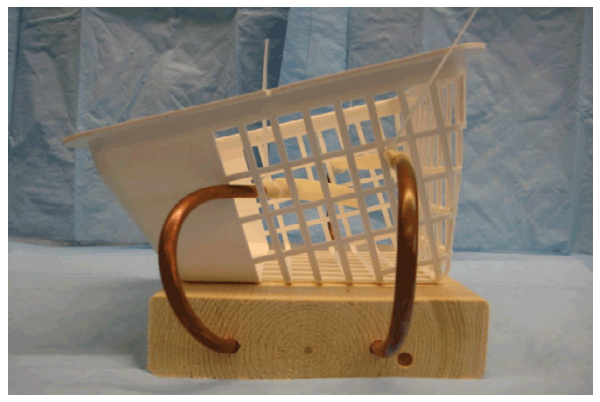

Figure 3: Vascular Trainer - View 3.

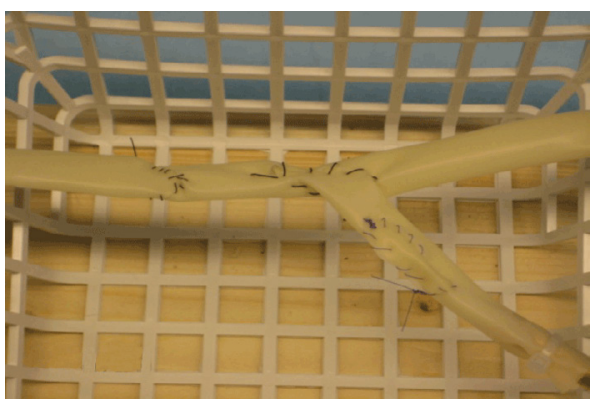

Figure 4: Vascular Trainer - View 4. 
Citation: Rodriguez-Feo CL, Brophy CM, Sexton KW (2014) Need Cost Effective Surgical Simulation, Send a Resident to the Hardware Store. J Vasc Med Surg 2: 150. doi: 10.4172/2329-6925.1000150
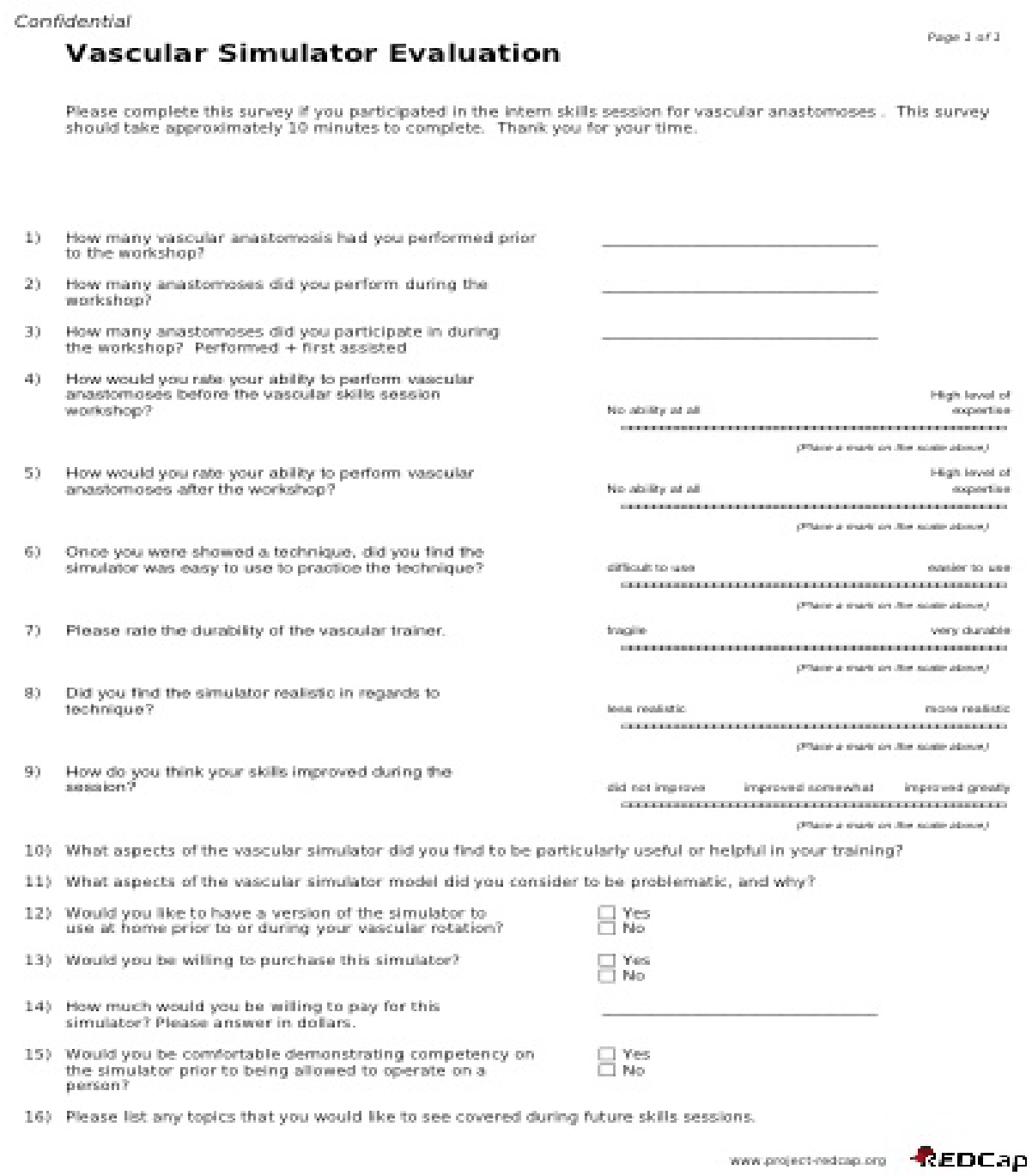

Figure 5: The online survey that was sent to twenty-six first year residents that participated in this research study.

demonstrating competency on the simulator prior to being able to perform the skill in the operating room.

\section{Discussion}

Every trainee, at some point, finds themself with the need to acquire a very simple skill, but the method is either too complicated or too costly. Consider trying to learn the names of trees while looking at a forest from a distance. The inefficiently of this style of learning will do nothing but hinder the learner. It makes more sense to learn the different types of leaves and consequently the names of trees before looking at a forest. In the same way, our proposed vascular trainer is isolating vascular techniques "away from the forest" and providing a step-wise approach to learning vascular surgery. The ergonomics of working at different angles and at different depths can be learned on this low-fidelity vascular trainer, which can allow numerous, "affordable" attempts.

The two components of fidelity as described by Miller are engineering and psychological fidelity. Engineering fidelity is defined by how a device embodies the physical characteristics of a task, which enables the acquisition of skills. Psychological fidelity creates an illusion of the real thing. Psychological fidelity and excessive engineering fidelity can be wasted if the lessons are not timely [10-12]. Using realistic human tissue is not timely when the operator doesn't understand the principles of basic vascular techniques. The current high fidelity simulators have both engineering and psychological fidelity, which provides for a realistic simulation but it is also very costly. The Vascular trainer has an appropriate level of engineering fidelity from which the ergonomics of basic vascular techniques can be learned at reasonable cost.

There has been a rise in the number of low-fidelity trainers in the area of laparoscopic surgery. The increase in "home simulators" is evidence that surgical education does not have to stop once you leave the hospital $[7,13]$. The ever-increasing demand for "home simulators" will be met by the creativity of many trainees who have felt the need for more practice to improve their surgical performance.

Evaluating surgical performance has traditionally been suboptimal in part to subjective and unreliable assessment of a resident's technical 


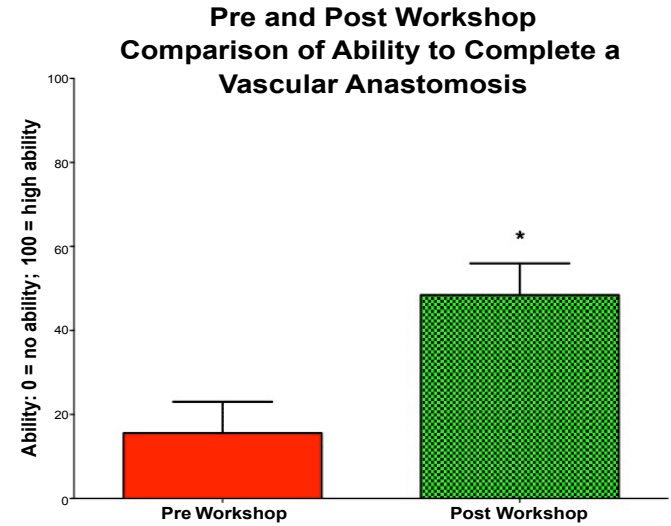

Figure 6: Graphical representation of a visual analog scale showing subjective pre and post workshop comparison of a resident's ability to perform a vascular anastomosis using the simulator. Statistical significance using a paired Wilcoxon matched-pairs sum test was reached between the pre and post workshop groups $(p=.009)$.

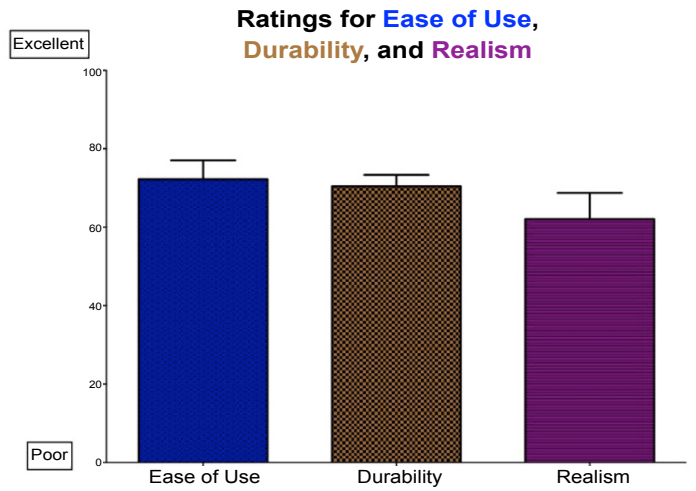

Figure 7: Graphical representation of a user's rating for Ease of Use, Durability, and Realism.

skills $[14,15]$. Isolating a skill allows for more efficient learning as well as enabling a more objective evaluation. Vascular surgery competency in the OR has been shown to model the performance of a resident in a laboratory-based setting by evaluating tangible measurements such as timeliness and grade of leakage of an anastomosis [2]. These criteria can be used to evaluate residents who practice on this vascular trainer.

Vascular surgery simulation has been a topic of interest in recent literature as the number of cases performed by vascular surgery resident's decreased [16]. Recent articles support the increasing use of simulation in vascular surgery residency [16-19]. In 2010, Bismuth et al. described a variety of vascular surgery simulators with examples: part task trainers (Limbs \& Things, Pontresina Vascular Course), computer programs (WebSet, other web-based tools), VR/haptic (Simbionix, Mentice, SimSuite), simulated patient environment (Orzone), integrated simulator model driven (METI Simulator, SimMan), and instructor driven (SimMan) [17]. A review article by Vikas et al. describes the role of vascular surgery simulation in all levels of a surgeon's training [19]. While simulation targeted toward senior residents is outside the scope of this article, the review articles states that junior trainees should be allowed to perform an anastomosis on a patient only after they have demonstrated proficiency outside the operating room. In addition, vascular surgery simulation can have the most benefit in novice learners where basic surgical technique can be practiced in low fidelity trainers like that described by Weale and Mitchell [19]. The model described by Weale and Mitchell also describes a low-fidelity vascular trainer, but with a more expensive design and without a trainee assessment [20]. The review article only describes one study comparing a vascular anastomosis performed by groups who practiced on either a low-fidelity bench trainer or a cadaveric model. Those who practiced on the cadaveric model performed better on a femoral anastomosis on an anesthetized pig19. Our aim is to provide an additional steppingstone in order to make the learning process easier and more economic.

The relevance of this study is the demand for a personal trainer, not in the subjective improvement reported by study participants. It has long been known that if you teach someone they will learn [21]. What remains to be effectively studied are comparative outcomes in low fidelity vs. high fidelity simulation in surgical education and the desires of the learner. The demand for a personal vascular trainer is evident by a universal desire shared by the residents. Future directions include showing whether an objective improvement of surgical competency in vascular anastomoses is dependent on the use of this vascular trainer.

\section{Conclusions}

This vascular trainer has proven to be an inexpensive and easy way to practice vascular anastomosis under supervision in the lab or on one's own at home.

\section{Acknowledgement}

The authors of this manuscript would like to thank Vanderbilt University Medical Center's Division of Vascular Surgery and Division of General Surgery.

\section{References}

1. LeBlanc V, Woodrow SI, Sidhu R, Dubrowski A (2008) Examination stress leads to improvements on fundamental technical skills for surgery. Am J Surg 196: 114-119.

2. Wilasrusmee C, Lertsithichai P, Kittur DS (2007) Vascular anastomosis model: relation between competency in a laboratory-based model and surgical competency. Eur J Vasc Endovasc Surg 34: 405-410.

3. Reznick RK, MacRae H (2006) Teaching surgical skills--changes in the wind. N Engl J Med 355: 2664-2669.

4. Kunkler K (2006) The role of medical simulation: an overview. Int J Med Robot 2: 203-210.

5. Torkington J, Smith SG, Rees BI, Darzi A (2000) The role of simulation in surgical training. Ann R Coll Surg Engl 82: 88-94.

6. Maran NJ, Glavin RJ (2003) Low- to high-fidelity simulation - a continuum of medical education? Med Educ 37 Suppl 1: 22-28.

7. Al-Abed Y, Cooper DG (2009) A novel home laparoscopic simulator. J Surg Educ 66: 1-2.

8. Dunkin B, Adrales GL, Apelgren K, Mellinger JD (2007) Surgical simulation: a current review. Surg Endosc 21: 357-366.

9. Székely (2003) Surgical simulators. Minim Invasive Ther Allied Technol 12 14-18.

10. Harris P, Taylor R, Thielke R, Payne J. Research electronic data capture (REDCap)--a metadata-driven methodology and workflow process for providing translational research informatics support. J Biomed Inform. 42: 377-381.

11. Miller RB (1953) Psychological considerations in the design of training equipment. Report no. WADC-TR-54-563, AD 71202. Wright Patterson Air Force Base, OH; Wright Air Development Center, USA.

12. Maran NJ, Glavin RJ (2003) Low- to high-fidelity simulation - a continuum of medical education? Med Educ 37 Suppl 1: 22-28.

13. Bokhari R, Bollman-McGregor J, Kahoi K, Smith M, Feinstein A, et al. (2010) Design, development, and validation of a take-home simulator for fundamental laparoscopic skills: using Nintendo Wii for surgical training. Am Surg 76: 583586. 
Citation: Rodriguez-Feo CL, Brophy CM, Sexton KW (2014) Need Cost Effective Surgical Simulation, Send a Resident to the Hardware Store. J Vasc Med Surg 2: 150. doi: 10.4172/2329-6925.1000150

Page 5 of 5

14. Szalay D, MacRae H, Regehr G, Reznick R (2000) Using operative outcome to assess technical skill. Am J Surg 180: 234-237.

15. Moorthy K, Munz Y, Sarker SK, Darzi A (2003) Objective assessment of technical skills in surgery. BMJ 327: 1032-1037.

16. Mitchell EL, Arora S, Moneta GL (2011) Ensuring vascular surgical training is on the right track. J Vasc Surg 53: 517-525.

17. Bismuth J, Donovan MA, O'Malley MK, El Sayed HF, Naoum JJ, et al. (2010) Incorporating simulation in vascular surgery education. J Vasc Surg 52: 1072 1080.
18. Dunkin B, Adrales GL, Apelgren K, Mellinger JD (2007) Surgical simulation: a current review. Surg Endosc 21: 357-366.

19. Pandey VA, Wolfe JH (2012) Expanding the use of simulation in open vascular surgical training. J Vasc Surg 56: 847-852.

20. Weale AR, Mitchell DC (2003) A do-it-yourself vascular anastomosis simulator Ann R Coll Surg Engl 85: 132.

21. Cook DA (2012) If you teach them, they will learn: why medical education needs comparative effectiveness research. Adv Health Sci Educ Theory Pract 17: 305-310. 